\title{
Type B intramural hematoma: thoracic endovascular aortic repair (TEVAR) or conservative approach?
}

\author{
Ignas B. Houben, Theodorus M. J. van Bakel, Himanshu J. Patel \\ Department of Cardiac Surgery, Frankel Cardiovascular Center, University of Michigan Health Center, Ann Arbor, MI, USA \\ Correspondence to: Himanshu J. Patel, MD. Joe D. Morris Collegiate Professor in Cardiac Surgery, Section Head, Adult Cardiac Surgery, University \\ of Michigan Frankel Cardiovascular Center, Ann Arbor, MI 48109-5864, USA. Email: hjpatel@med.umich.edu.
}

Submitted Mar 21, 2019. Accepted for publication May 22, 2019.

doi: $10.21037 /$ acs.2019.05.18

View this article at: http://dx.doi.org/10.21037/acs.2019.05.18

\section{Introduction}

An intramural hematoma (IMH) is the second most common presentation of acute aortic syndrome, with an estimated occurrence of 1.98/100,000 person-years (1). In the majority of cases, an IMH is located in the descending thoracic aorta. The clinical symptoms are similar to those of aortic dissection (AD), yet the population is older, the morphology different, and the mortality rate lower compared to AD. IMH was first described by Krukenberg in 1920 (2). Ever since, the pathophysiology of the disease is yet to be elucidated. We currently have only retrospective series available to describe the natural history. This is partly due to relatively low incidence of the disease itself. The onset of IMH has been associated with the occurrence of intimal micro-tears, vasa-vasorum hemorrhage and undiscovered penetrating atherosclerotic ulcers $(\mathrm{PAU})(3,4)$.

\section{Wolf in sheep's clothing?}

Treatment of a type B IMH starts with medical management, by way of controlling blood pressure. Operative management is reserved for patients who present with complications such as frank rupture, visceral malperfusion, intractable pain, or other signs of impending aortic rupture. The majority of these complicated cases can be managed with thoracic endovascular aortic repair (TEVAR), with recent studies describing better outcomes compared to open surgical repair $(5,6)$. The early-mortality rate of patients treated with open $v s$. endovascular repair has been shown to be $16 \%$ vs. $5 \%$ and the 3 -year mortality rate was $23 \% v s .7 \%$ (7).

Clinical decision-making for uncomplicated type B IMHs is more complex, as patients with uncomplicated
IMHs have either complete regression during follow-up, or may develop adverse aortic remodeling or progression into classic $\mathrm{AD}$. In a non-resolving IMH, most adverse events happen in the first year after onset (8). For now, the best radiographic predictor for adverse events in uncomplicated cases is the outer diameter of the aortic wall, similar to other acute aortic syndromes (9). IMH-specific predictors of adverse events include the presence of ulcer like projections (ULP) and local wall thickness $>11 \mathrm{~mm}$ (Figure 1) $(5,10,11)$. The latter predictor, however, was found in a study from 2003 that analyzed a cohort of 25 patients with type A IMH (10). The nomenclature in the literature may be confusing, as IMH and PAU can be considered points on a spectrum of intramural aortic pathologies. Originally PAU was described as a pathologic diagnosis (12). Contemporary clinical diagnosis is based upon computed tomography (CT) and therefore the term ulcer-like projection (ULP) better reflects radiographic diagnosis. For IMH treatment, it is important to understand the etiologic differences between ULPs. As described previously by Williams et al. the branch artery pseudoaneurysm may be benign and could be treated with optimal medical treatment (13) (Figure 2). Acute focal intimal disruptions, whether or not due to atherosclerotic ulcers, should be considered for TEVAR $(14,15)$. Subacute or chronic focal intimal disruptions may be treated more conservatively (14). If CT quality allows, tiny intimal disruptions $(<3 \mathrm{~mm})$ should be distinguished from focal intimal disruptions $(>3 \mathrm{~mm})$, as the risk for adverse events differ significantly (16). An $\mathrm{IMH}$ with tiny intimal disruption should, however, be followed closely in the first year after onset as they may progress into focal intimal disruptions (16). 

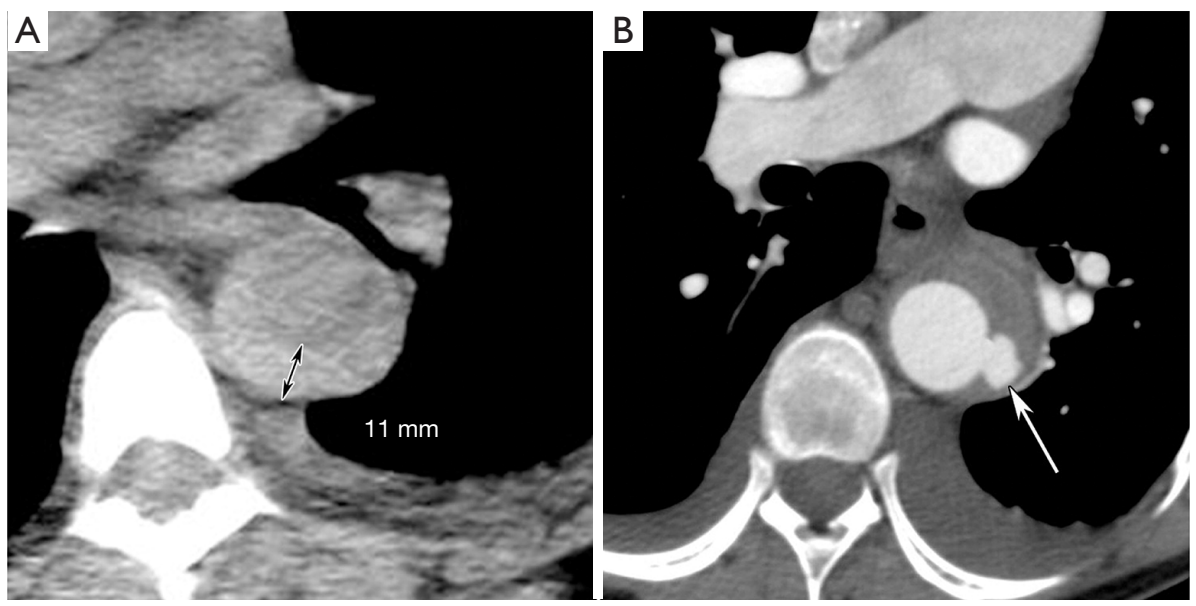

Figure $1 \mathrm{IMH}$ predicting factors for adverse events. (A) Axial nonenhanced CT image shows an IMH thickness of $11 \mathrm{~mm}$ (double-headed arrow). The patient is at increased risk for progression and mortality. (B) Axial contrast-enhanced CT image shows an ulcer like projection (arrow) with localized contrast enhancement extending from the aortic lumen into the IMH and a visible communication. Reprinted with permission from Gutschow et al. (3). IMH, intramural hematoma; CT, computed tomography.
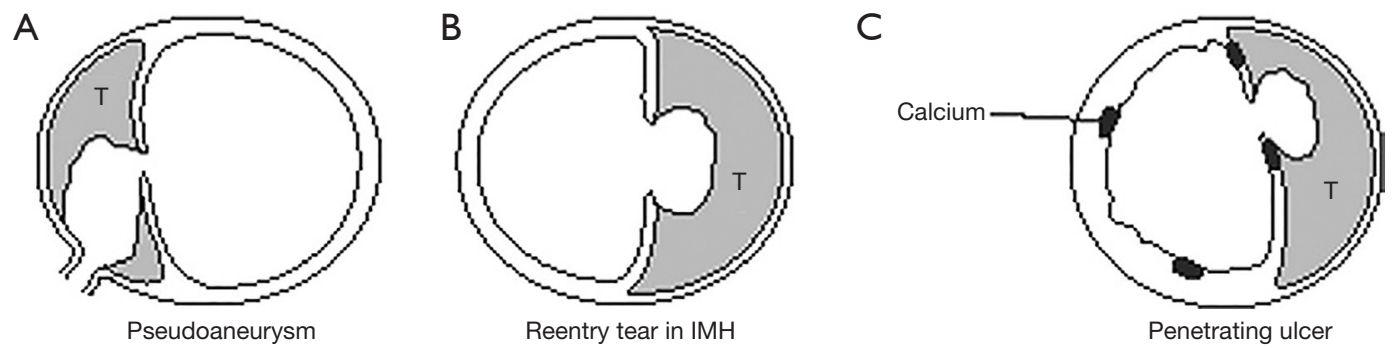

Figure 2 Schematic representation of aortic cross section in different pathologies. As these diagrams show, the radiographic signs of ulcer like projection can encompass three potential pathologic entities. (A) The first represents a typical branch artery pseudoaneurysm, the natural history of which is benign ( $\mathrm{T}=$ thrombus). (B) The middle schema shows a re-entry tear developing in intramural hematoma (IMH), with local excavation of the mural thrombus. As the hematoma resolves, it can be left with an appearance of a penetrating ulcer. The diagnosis of entry tear would have been possible only if the original imaging study, in which the IMH was "fresh", was available. (C) The final schema represents the original PAU as described by Stanson et al. (12). Reprinted with permission from Williams et al. (13).

\section{TEVAR challenges}

Endovascular repair of type B IMHs pose challenges similar to those encountered when treating type B AD (17). Since the mechanical properties of the IMH change during follow-up, timing of TEVAR has implications on the environment in which the stent-graft is deployed. In the acute phase, the hematoma expands and the aortic lumen is compromised most. During follow-up, the hematoma thromboses and resolves, increasing the aortic lumen over time (18). This makes stent-graft sizing challenging. In the acute phase, the stent-graft can potentially be undersized, increasing the risk of stent-graft migration and type 1 endoleak. Measuring the total aortic radius including the $\mathrm{IMH}$, on the other hand, comes with the risk of excessive oversizing and related complications. The elevated stress distributions across the wall may cause collapse of the stent-graft (Figure 3). Furthermore, apical bare metal stents and excessive balloon dilation can induce new entrytears in friable aortic tissue $(6,20)$. Therefore, if the aortic dimension is not increasing over time, delaying treatment is advised (15). After the subacute phase, the intimal layer stiffens and favorable aortic remodeling can be harder to achieve (21). In this phase, stent-graft sizing will rely more on the true lumen diameter, as the stiffened intima may not 


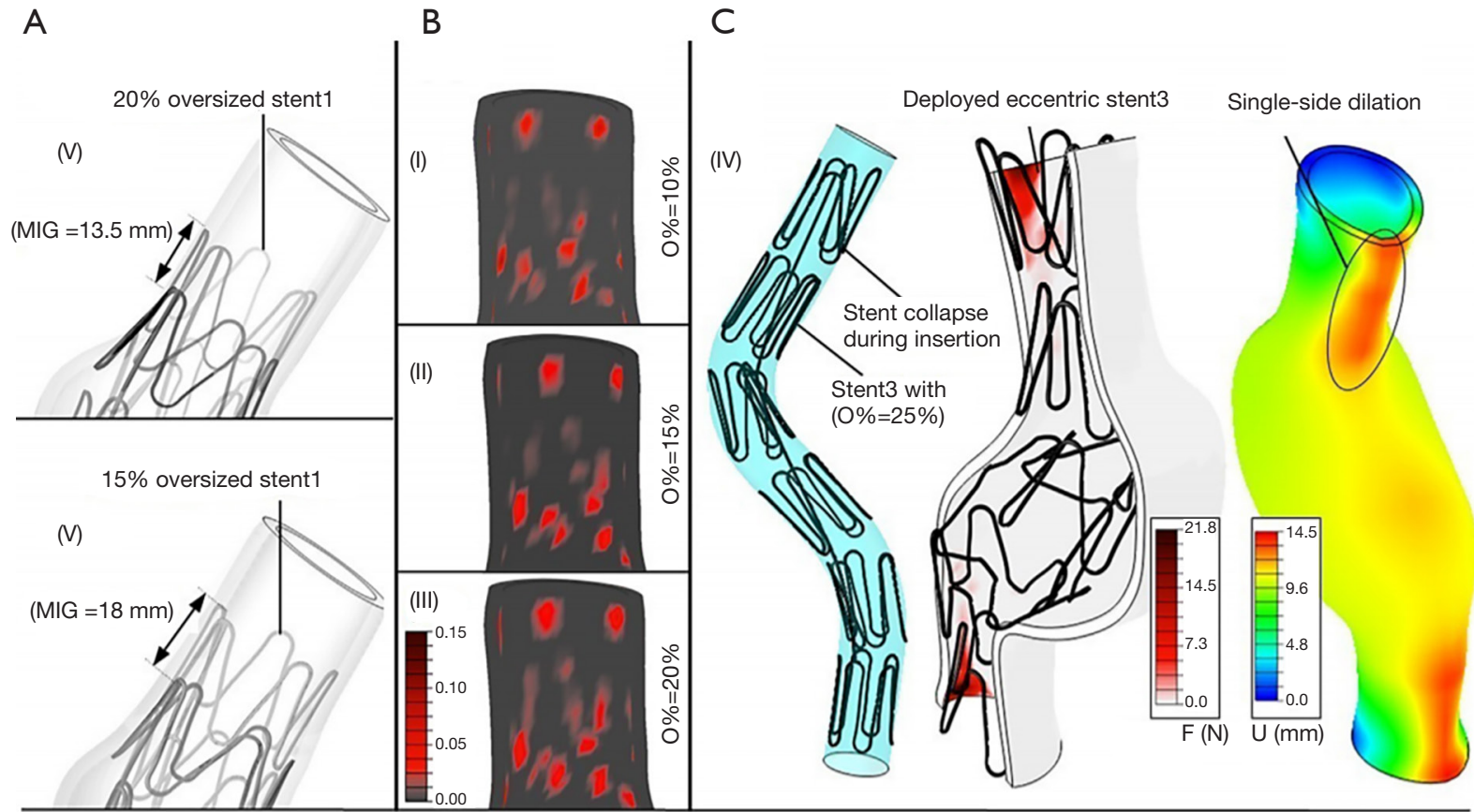

Figure 3 Schematic depiction of stent sizing and the associated forces calculated using a computational model. (A) Impact of $20 \%$ oversizing on proximal landing zone stent migration; (B) contact pressure stresses (MPa) in the proximal landing zone for different percentages of oversizing; (C) excessive oversizing with stent-graft collapse and increased dilatation $(\mathrm{U})$ in the landing zones. Reprinted with permission from Altnji et al. (19). MIG, migration; O\%, percentage of oversizing; F, force (Newton); U, displacement (millimeter).

allow much radial oversizing.

The adverse aortic remodeling, as seen in older patients, can result in angulation and tortuosity of the diseased aorta, which increases hemodynamic displacement forces acting on the surface of the stent-graft (22). In this anatomic configuration, an extended length of repair is often necessary to achieve appropriate sealing in the proximal and distal landing zones $(22,23)$. Extended repair also increases the risks of stroke, spinal cord ischemia and type 3 endoleak at the intermodular junctions $(24,25)$. Finally, current stent-grafts for TEVAR are 50-200 times stiffer than healthy aortic tissue $(26,27)$. This increased stiffness of the aorta following stent-graft deployment can increase stresses in the untreated segments of the aortic wall (28). Furthermore, left ventricular stroke work is estimated to increase up to $26 \%$ as a consequence of stent-graft induced descending aortic stiffening, resulting in adverse left ventricular remodeling (29).

\section{Conclusions}

Uncomplicated type B IMHs are optimally treated with medical management. TEVAR is reserved for patients with complications and requires an experienced surgeon who can identify patient-specific challenges that increase the risk of the procedure. Factors such as the presence of ULPs should be taken into consideration for the decision to operate and reduce the long-term risk of aortic rupture.

However, large prospective or retrospective cohort data, generating IMH-specific outcomes are lacking. Contemporary decision-making is based on: (I) retrospective cohorts from $>10$ years ago, comprising no more than 66 patients with isolated IMHs; (II) clinical experience; and (III) acute aortic syndrome reports with a majority describing classic double barrel ADs.

Further research is necessary and should focus on providing a stratified risk model coupled with a natural history assessment in a large cohort and should be contrasted to that seen with classic $\mathrm{AD}$.

\section{Acknowledgments}

Dr. HJ Patel was generously supported by the Joe D. Morris Collegiate Professorship, the David Hamilton Fund and the 
Phil Jenkins Breakthrough Fund.

\section{Footnote}

Conflicts of Interest: The authors have no conflicts of interest to declare.

\section{References}

1. DeMartino RR, Sen I, Huang Y, et al. PopulationBased Assessment of the Incidence of Aortic Dissection, Intramural Hematoma, and Penetrating Ulcer, and Its Associated Mortality From 1995 to 2015. Circ Cardiovasc Qual Outcomes 2018;11:e04689.

2. Krukenberg E. Contribution to the question of dissecting aneurysm. Beitr Pathol Anat Allg Pathol 1920;67:329-51.

3. Gutschow SE, Walker CM, Martínez-Jiménez S, et al. Emerging Concepts in Intramural Hematoma Imaging. RadioGraphics 2016;36:660-74.

4. Park KH, Lim C, Choi JH, et al. Prevalence of Aortic Intimal Defect in Surgically Treated Acute Type A Intramural Hematoma. Ann Thorac Surg 2008;86:1494-500.

5. Ganaha F, Miller DC, Sugimoto K, et al. Prognosis of aortic intramural hematoma with and without penetrating atherosclerotic ulcer: A clinical and radiological analysis. Circulation 2002;106:342-8.

6. Patel HJ, Williams DM, Upchurch GR, et al. The challenge of associated intramural hematoma with endovascular repair for penetrating ulcers of the descending thoracic aorta. J Vasc Surg 2010;51:829-35.

7. Evangelista A, Czerny M, Nienaber C, et al. Interdisciplinary expert consensus on management of type $\mathrm{B}$ intramural haematoma and penetrating aortic ulcer. Eur J Cardiothorac Surg 2015;47:209-17.

8. Sailer AM, Nelemans PJ, Hastie TJ, et al. Prognostic significance of early aortic remodeling in acute uncomplicated type B aortic dissection and intramural hematoma. J Thorac Cardiovasc Surg 2017;154:1192-200.

9. Riambau V, Böckler D, Brunkwall J, et al. Editor's Choice - Management of Descending Thoracic Aorta Diseases: Clinical Practice Guidelines of the European Society for Vascular Surgery (ESVS). Eur J Vasc Endovasc Surg 2017;53:4-52.

10. Song JM, Kim HS, Song JK, et al. Usefulness of the initial noninvasive imaging study to predict the adverse outcomes in the medical treatment of acute type A aortic intramural hematoma. Circulation 2003;108 Suppl 1:II324-8.

11. von Kodolitsch Y, Csösz SK, Koschyk DH, et al.
Intramural hematoma of the aorta: predictors of progression to dissection and rupture. Circulation 2003; 107:1158-63.

12. Stanson AW, Kazmier FJ, Hollier LH, et al. Penetrating atherosclerotic ulcers of the thoracic aorta : natural history and clinicopathologic correlations. Ann Vasc Surg 1986;1:15-23.

13. Williams DM, Cronin P, Dasika N, et al. Aortic Branch Artery Pseudoaneurysms Accompanying Aortic Dissection. Part II. Distinction from Penetrating Atherosclerotic Ulcers. J Vasc Interv Radiol 2006;17:773-81.

14. Moral S, Cuéllar H, Avegliano G, et al. Clinical Implications of Focal Intimal Disruption in Patients With Type B Intramural Hematoma. J Am Coll Cardiol 2017;69:28-39.

15. Patel HJ, Sood V, Williams DM, et al. Late outcomes with repair of penetrating thoracic aortic ulcers: the merits of an endovascular approach. Ann Thorac Surg 2012;94:51622; discussion 522-3.

16. Moral S, Ballesteros E, Roque $M$, et al. Intimal disruption in type B aortic intramural hematoma. Does size matter? A systematic review and meta-analysis. Int J Cardiol 2018;269:298-303.

17. van Bakel TMJ, Figueroa CA, van Herwaarden JA, et al. Commentary: Challenges of Thoracic Endovascular Aortic Repair for Type B Aortic Dissection. J Endovasc Ther 2018;25:578-80.

18. Evangelista A, Dominguez R, Sebastia C, et al. Long-term follow-up of aortic intramural hematoma: Predictors of outcome. Circulation 2003;108:583-9.

19. Altnji HE, Bou-Saï B, Walter-Le Berre H. Morphological and stent design risk factors to prevent migration phenomena for a thoracic aneurysm: a numerical analysis. Med Eng Phys 2015;37:23-33.

20. Jánosi RA, Gorla R, Tsagakis K, et al. Thoracic endovascular repair of complicated penetrating aortic ulcer: An 11-year single-center experience. J Endovasc Ther 2016;23:150-9.

21. Peterss S, Mansour AM, Ross JA, et al. Changing Pathology of the Thoracic Aorta From Acute to Chronic Dissection: Literature Review and Insights. J Am Coll Cardiol 2016;68:1054-65.

22. Figueroa CA, Taylor CA, Chiou AJ, et al. Magnitude and direction of pulsatile displacement forces acting on thoracic aortic endografts. J Endovasc Ther 2009;16:350-8.

23. Kasirajan K, Milner R, Chaikof EL. Late complications of thoracic endografts. J Vasc Surg 2006;43 Suppl A:94A-99A.

24. Prasad A, To LK, Gorrepati ML, et al. Computational 
analysis of stresses acting on intermodular junctions in thoracic aortic endografts. J Endovasc Ther 2011;18:559-68.

25. Gutsche JT, Cheung AT, McGarvey ML, et al. Risk factors for perioperative stroke after thoracic endovascular aortic repair. Ann Thorac Surg 2007;84:1195-200; discussion 1200.

26. Santos IC, Rodrigues A, Rocha LA, et al. Mechanical properties of stent-graft materials. Proc Inst Mech Eng Pt L J Mater Des Appl 2012;226:330-41.

27. de Beaufort HWL, Coda M, Conti M, et al. Changes

Cite this article as: Houben IB, van Bakel TM, Patel HJ. Type $B$ intramural hematoma: thoracic endovascular aortic repair (TEVAR) or conservative approach? Ann Cardiothorac Surg 2019;8(4):483-487. doi: 10.21037/acs.2019.05.18 in aortic pulse wave velocity of four thoracic aortic stent grafts in an ex vivo porcine model. PLoS One 2017;12:e0186080.

28. van Bakel TMJ, Burris NS, Patel HJ, et al. Ascending aortic rupture after zone 2 endovascular repair: a multiparametric computational analysis. Eur J Cardiothorac Surg 2019. [Epub ahead of print].

29. van Bakel TMJ, Arthurs CJ, Nauta FJH, et al. Cardiac remodelling following thoracic endovascular aortic repair for descending aortic aneurysms. Eur J Cardiothorac Surg 2019;55:1061-70. 